\title{
Influência dos custos de produção e de transporte para a agricultura familiar e sua relação com o desenvolvimento regional: o caso da feira municipal de Guanambi (BA)
}

\author{
Leise Kelli de Oliveira \\ Universidade Federal de Minas Gerais - Belo Horizonte - MG - Brasil \\ ORCID: 0000-0002-4756-4183 \\ Isadora Alves Barbosa \\ Universidade Federal de Minas Gerais - Belo Horizonte - MG - Brasil \\ ORCID: 0000-0002-5452-6791 \\ Leonardo Herszon Meira \\ Universidade Federal de Pernambuco - Recife - PE - Brasil \\ ORCID: 0000-0002-3369-5801 \\ Isabelly Christiny Monteiro de Souza Pinto \\ Universidade Federal de Pernambuco - Recife - PE - Brasil \\ ORCID: 0000-0003-3771-0316
}

\section{Resumo}

A agricultura familiar desempenha um papel fundamental na geração de renda e no abastecimento dos centros urbanos. Contudo, ainda pouco se conhece sobre o perfil de produtores da agricultura familiar, principalmente da região Nordeste do Brasil. Diante disso, neste artigo é analisado a influência regional da feira municipal de Guanambi (BA), formada em sua maioria por agricultores familiares. As análises foram fundamentadas em dados de pesquisa de campo com agricultores familiares e consumidores da feira livre de Guanambi (BA), além de observações no local. Entre os resultados obtidos, identificou-se que a feira livre de Guanambi desempenha articulações urbanas e regionais com diversos municípios e localidades rurais circunvizinhas, pois a maioria das propriedades rurais localizam-se até $100 \mathrm{~km}$ da feira de Guanambi. Os agricultores familiares em sua maioria desconhecem custos de produção e transporte, confirmando precariedade na gestão e no controle dos custos nas propriedades agrícolas familiares. Em relação aos consumidores, a qualidade dos produtos e o preço das mercadorias atraem consumidores de até $19 \mathrm{~km}$ de Guanambi. Contudo, a falta de transporte intermunicipal é um fato observado nas viagens tanto de produtores quanto de consumidores. Os resultados deixam evidente a importância do aprimoramento das de políticas públicas com a inclusão de programas de 
gestão financeira e de cálculo de custos de transportes para a consolidação da agricultura familiar no contexto regional.

Palavras-chave: Agricultura familiar. Feira livre municipal. Custos de transporte e produção.

\section{Influence of production and transportation costs for family farming and its relationship with regional development: the case of the municipal marketplace in Guanambi (BA)}

\section{Abstract}

Family farming plays a key role in the generation of income and supplying urban centres with fresh food. However, the knowledge about the profile of family farmers, especially in the Northeast of Brazil is scarce. In light of this, this paper analyzes the regional influence of the Guanambi (BA) municipal marketplace, formed mostly by family farmers. The analyzes were based on data from field research with family farmers and consumers at the free market in Guanambi (BA), in addition to on-site observations. Among the results, it was identified that the Guanambi marketplace contributes to regional development since most rural properties are located within $100 \mathrm{~km}$ of the Guanambi. Most family farmers are unaware of production and transportation costs, confirming the precariousness of the management and control of costs on family farms. Regarding consumers, the quality of products and the price of goods attract consumers up to $19 \mathrm{~km}$ from Guanambi. However, the lack of intercity transport is observed in the transportation mode used by producers and consumers. The results make evident the importance of improving public policies with the inclusion of financial management programs and transportation cost calculations for the consolidation of family farming in the regional context.

Keywords: Family farming. Open market. Production and transportation cost.

\section{Influencia de los costos de producción y transporte para la agricultura familiar y su relación con el desarrollo regional: el caso de la feria municipal de Guanambi (BA) \\ Resumen}

La agricultura familiar juega un papel clave en la generación de ingresos y el suministro de centros urbanos. Sin embargo, se sabe poco sobre el perfil de los agricultores familiares, especialmente en el noreste de Brasil. A la luz de esto, este artículo analiza la influencia regional de la feria municipal de Guanambi (BA), formada principalmente por agricultores familiares. Los análisis se basaron en datos de investigaciones de campo con agricultores familiares y consumidores en el mercado libre en Guanambi (BA), además de observaciones in situ. Entre los resultados obtenidos, se identificó que el mercado abierto de Guanambi tiene vínculos urbanos y regionales con varios municipios circundantes y ubicaciones rurales, ya que la mayoría de las propiedades rurales se encuentran dentro de los $100 \mathrm{~km}$ de la feria de Guanambi. La mayoría de los agricultores familiares desconocen los costos de producción y transporte, lo que confirma la precariedad en el manejo y control de los costos en las granjas familiares. En cuanto a los consumidores, la calidad de los productos y el precio de los bienes atraen a consumidores de hasta $19 \mathrm{~km}$ de Guanambi. Sin embargo, la falta de transporte interurbano es un hecho observado en los viajes tanto de productores como de consumidores. Los resultados ponen de manifiesto la importancia de mejorar las políticas públicas con la inclusión de programas de gestión financiera y cálculos de costos de transporte para la consolidación de la agricultura familiar en el contexto regional.

Palabras clave: Agricultura familiar. Mercado abierto municipal. Costos de producción y transporte. 


\section{Introdução'}

Com o aumento da população nos centros urbanos é recorrente a preocupação com o abastecimento urbano em quantidade e qualidade de produtos. Nesse contexto, a agricultura familiar desempenha um importante papel, produzindo os produtos básicos na alimentação do brasileiro, como mandioca, feijão e milho fornecidos majoritariamente por fazendas de agricultura familiar (IBGE, 2006). Além disso, a agricultura familiar contribui na manutenção e geração de empregos, diminuição do êxodo rural e geração de recursos para as famílias de baixa renda (OLIVEIRA et al., 2016).

Apesar da discussão sobre a agricultura familiar ter ganhado visibilidade em decorrência de questões associadas ao desenvolvimento sustentável, geração de emprego e renda, segurança alimentar e desenvolvimento regional, existe a necessidade de estudos específicos em virtude da heterogeneidade do setor agrícola familiar (MACHADO; SILVA, 2004). Segundo Ferreira et al. (2009), trabalhos que caracterizam a agricultura familiar em regióes pouco estudadas são relevantes, uma vez que esses podem atuar como um instrumento confiável para a elaboração de políticas públicas de desenvolvimento regional, por retratar as especificidades e a realidade local.

Para Santos et al. (2015), as políticas de estímulo à agricultura, pesquisa, tecnologias, sistemas de financiamento e comercialização agrícola visam a industrialização brasileira e são destinadas, em sua maioria, à atividade agrícola em grande escala, muitas vezes desconsiderando a agricultura familiar. Deste modo, embora a agricultura familiar desempenhe um papel econômico e social muito importante (OLIVEIRA et al., 2016), tanto em escala regional quanto nacional, a realidade do setor é frequentemente marcada por dificuldades de escoamento da produção (MACHADO; SILVA; 2004). De acordo com Machado e Silva (2004), o transporte e a distribuição são os principais problemas que os produtores agrícolas familiares encontram para atuarem no mercado. Além disso, alguns produtos, como por exemplo, as hortaliças, geram maior dificuldade para distribuição por apresentarem alta perecibilidade e podem prejudicar o desenvolvimento regional.

As feiras são uns dos principais canais de comercialização dos produtos da agricultura familiar (RIBEIRO et al., 2014; CRUZ et al., 2020), sendo importantes na diversificação da economia local, na geração de renda para os agricultores familiares e na oferta de alimentos saudáveis para os residentes das áreas urbanas. As feiras livres são pontos de venda tradicionais que atuam como alternativas para o produtor vender seus produtos diretamente ao consumidor (MACHADO; SILVA, 2004), possibilitando maior proximidade entre produtores e consumidores, maior lucro ao agricultor familiar e menor preço ao consumidor (NASCIMENTO; BESKOW, 2015).

Neste contexto, este artigo tem como objetivo analisar a influência dos custos de produção e de transporte para a agricultura familiar e sua relação com o

\footnotetext{
${ }^{1}$ Este artigo traz os principais resultados da dissertação de mestrado da segunda autora, orientada pela primeira autora Curso de Mestrado em Geotecnia e Transportes da UFMG. Os demais coautores contribuíram com a revisão de literatura e participaram conjuntamente da análise e discussão dos dados.
} 
desenvolvimento regional, analisando o caso da feira municipal de Guanambi (BA). $O$ intuito é mostrar a influência regional de uma feira municipal cujos comerciantes são, em sua maioria, agricultores familiares e a importância de políticas públicas para a consolidação desse tipo de comércio para o fortalecimento da agricultura familiar em um contexto regional. Guanambi (BA) foi escolhida para esse estudo por ser um subcentro regional definido pelo IBGE (2008). Além disso, nada leva a crer que a situação ora estudada seja diferente em outros polos regionais brasileiros.

Além do objetivo proposto, este trabalho contribui para reduzir a carência de estudos com foco na agricultura familiar para o abastecimento urbano (OLIVEIRA et al., 2016). Ainda, este artigo apresenta um perfil dos agricultores familiares e dos consumidores da feira municipal de Guanambi (BA). Petrini et al. (2017) salientam a importância da identificação da realidade por meio do próprio agricultor familiar, conforme é realizado neste estudo para aqueles que comercializam na feira municipal de Guanambi (BA).

Para atingir o objetivo proposto esse artigo está estruturado em 7 seções. Após esta introdução, a seção 2 faz uma revisão sistemática da literatura sobre a influência do transporte na agricultura familiar. Em seguida a seção 3 caracteriza a região de Guanambi (BA). A seguir, apresenta-se a metodologia utilizada nesse trabalho. A seção 5 apresenta o perfil dos agricultores familiares que atuam na feira livre de Guanambi, discutindo a influência dos custos de produção e de transporte para a agricultura familiar e sua relação com o desenvolvimento regional. Já a seção 6 traça um perfil dos consumidores da feira livre de Guanambi e discute a importância deles para a consolidação da agricultura familiar. Por fim, a seção 7 tece as considerações finais e traz recomendações para trabalhos futuros.

\section{A influência do transporte na agricultura familiar}

À medida que a população mundial aumenta, as áreas rurais tendem a acompanhar esse crescimento para abastecer os centros urbanos. Como consequência, a agricultura familiar pode ter vantagem na produção e fornecimento de produtos para mercados próximos aos locais de produção, visto que quanto menor a distância percorrida entre o campo e os locais de abastecimento, menor será o custo de transporte (CURRAN-COURNANE et al., 2016).

Neste sentido, áreas produtoras em regiões densamente povoadas e com alta concentração de renda têm um acesso preferencial aos grandes mercados, além de reduzidos custos de transporte. Há dessa forma, uma relação positiva entre o grau de urbanização e a perpetuidade das empresas agrícolas (BERTONI; CAVICCHIOLI, 2016). Segundo Faús (2014), dados geográficos e variações socioeconômicas são influenciadas pelas ligações rurais-urbanas e suas condições.

O transporte é o meio de ligação das áreas produtoras da agricultura familiar e os locais de comercialização. A precariedade no armazenamento e no transporte são os principais processos responsáveis por grande parte da perda da produção proveniente da agricultura familiar (MICCOLI et al., 2016). Contudo, poucos são os agricultores familiares que tem conhecimento além do processo de plantio e colheita, incluindo informação sobre o processo de transporte e comercialização dos produtos (CURRAN-COURNANE et al., 2016). Esta falta de conhecimento acarreta um elevado grau de informalidade, com precificação dos produtos sendo 
um resultado do ambiente e não dos custos envolvidos. As dificuldades encontradas pelos agricultores, principalmente associadas ao transporte e acesso ao mercado consumidor e as vantagens da produção próximo ao mercado consumidor são relatadas por Michalscheck et al. (2018), Bertoni e Cavicchioli (2016), Miccoli et al. (2016), Coelho e Favareto (2008) e Faús (2014).

A relação entre a distância do estabelecimento rural ao mercado consumidor e o lucro foi foco dos estudos de Bromley (2009), Grande (2011) e Pölling et al. (2017), avaliando os obstáculos associados às grandes distâncias entre as propriedades rurais e o centro urbano, tais como a dificuldade na venda da produção e a redução dos lucros em decorrência dos elevados custos de transporte. O impacto da distância na rentabilidade, no tipo de produção agrícola e padrões de uso da terra foi analisado por Vandercasteelen et al. (2017), Headey e Jayne (2014), Garrett et al. (2013), Taiwo (2014), Abdullah et al. (2017), Holland et al. (2016), Krishna et al. (2017) e Babigumira et al. (2014). As vantagens da proximidade entre a propriedade agrícola e o mercado, conforme proposto nas redes alimentares alternativas (AFNs) e nas áreas agrícolas peri-urbanas foi analisado por Paül et al. (2013), Newman et al. (2015) e Wästfelt et al. (2016). Coelho e Favareto (2008) analisaram as dificuldades de acesso aos mercados consumidores de produtos agrícolas e a atuação de intermediários na região do Vale da Ribeira no Estado de São Paulo. Não foi identificado estudo para o nordeste brasileiro, onde há intensa atuação agrícola familiar e onde concentram-se $47,2 \%$ dos produtores agrícolas familiares (IBGE, 2017).

Os estudos analisados permitem concluir que a literatura margeia as questões referentes a importância do transporte para a agricultura familiar, confirmando a necessidade de estudos para compreender a importância do transporte para a agricultura familiar. Apesar de ser uma temática com relevância social e científica, a maioria dos estudos priorizam o agronegócio e as grandes fazendas ou temas como cooperativas e agricultura orgânica. A influência do transporte para a agricultura familiar, principalmente sobre o aspecto do pequeno agricultor familiar ainda carece de estudos, reafirmando a importância deste trabalho. Desta forma, este artigo pretende contribuir para reduzir esta lacuna, por meio de um estudo no município de Guanabi (BA).

\section{Caracterização do município de Guanambi (BA)}

O município de Guanambi está distante 796 quilômetros de Salvador e é interligado à capital pelas rodovias BR-030, BA-262 e BR-324. A proximidade com os municípios de Caetité, Palmas de Monte Alto, Pindaí e Candiba faz com que atue como uma forte influência na área comercial (IBGE, 2010). O potencial econômico do município está relacionado ao comércio e à prestação de serviços, configurando a cidade como polo regional. Um dos fatores que contribui para a cidade adquirir esse perfil é sua localização, interligando o estado da Bahia a Minas Gerais, atuando como importante rota de escoamento de mercadorias.

Segundo o IBGE (2010), a população de Guanambi era de 78.833 habitantes em 2010, sendo estes distribuídos 79\% na área urbana e $21 \%$ na rural. Em termos de influência regional, o município de Guanambi é classificado como centro subregional $\mathrm{A}$, que no Brasil é composto por 85 cidades, onde cada uma delas possui, 
em média, 95 mil habitantes e 112 relacionamentos (IBGE, 2008). Ademais, a categoria caracteriza-se por ofertar uma grande diversidade de serviços nos setores do comércio, educação, saúde, jurídica, transporte e outros, atraindo pessoas da região.

A cidade de Guanambi exerce influência sobre o centro sub-regional B, Bom Jesus da Lapa; sobre os centros de zona A, Caetité, Santa Maria da Vitória e Macaúbas; sobre os centros de zona $B$, Ibotirama e Caculé. Influencia também os centros locais: Candiba, Carinhanha, Feira da Mata, luiú, Jacaraci, Malhada, Matina, Palmas de Monte Alto, Pindaí, Riacho de Santana, Sebastião Laranjeiras, Urandi, Licínio de Almeida, Mortugaba, Rio do Antônio, Ibiassucê, Botuporã, Igaporã, Lagoa Real, Tanque Novo, Paratinga, Serra do Ramalho e Sítio do Mato (IBGE, 2008).

No contexto da agricultura familiar, Pereira (2010) analisou a expansão do município de Guanambi e identificou o papel expressivo desempenhado pela agricultura e pelo comércio. Segundo o autor, o município de Guanambi é tradicionalmente associado à força do seu centro comercial. Esse fenômeno fica mais evidente nas segundas e quintas-feiras, dias mais tradicionais de feira livre no município e onde há uma grande atração de pessoas de outras cidades, impulsionando o comércio local (PEREIRA, 2013).

No tocante aos produtos cultivados, segundo informações do sistema de dados estatísticos (SIDE, 2018), as culturas que obtiveram maiores volumes de produção na cidade em 2016 foram o tomate e a banana, com 67\% e 12\% respectivamente. Atualmente, o Mercado Municipal de Guanambi, onde a feira livre é realizada, comercializa além de produtos originários da agricultura, carnes, peixes, leite e derivados, utensílios domésticos, dentre outros, atraindo compradores e vendedores de locais variados.

\section{Metodologia}

O estudo ora apresentado caracteriza-se como exploratório, pois realizou-se um estudo de caso, descrevendo as características envolvidas da agricultura familiar para o abastecimento da feira livre de Guanambi. Para tal, os dados foram coletados aplicando-se questionários aos feirantes (pequenos agricultores familiares) e aos consumidores dos produtos comercializados na feira livre. O questionário foi elaborado para permitir relacionar questões relacionadas ao transporte $\mathrm{e}$ comercialização dos produtos da agricultura familiar, com o local de comercialização (no caso, a feira livre) e o perfil dos consumidores. A Figura 1 apresenta as principais informações obtidas por meio do questionário com a pesquisa de campo. 
Figura 1: Principais informações obtidas com o questionário na pesquisa de campo
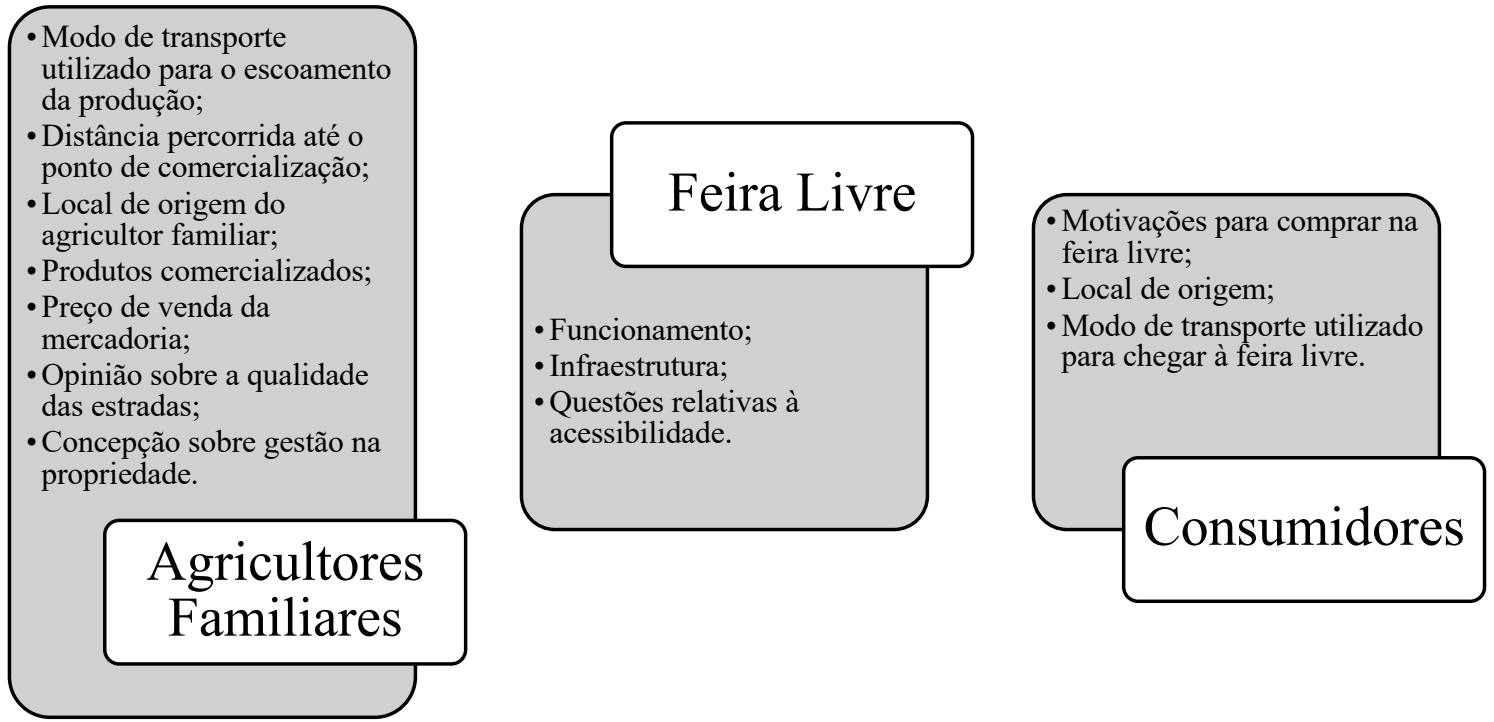

Fonte: elaborado pelos autores (2018).

A aplicação do questionário aconteceu in loco, entre os meses de março e agosto de 2018. Na feira livre de Guanambi há comerciantes que são agricultores familiares e comercializam produtos produzidos em suas propriedades rurais e outros comerciantes que apenas compram produtos para revenda. Do total de comerciantes abordados para responder o questionário, $68 \%$ eram agricultores familiares. A amostra foi dimensionada para uma confiança de $90 \%$ e $5 \%$ de erro amostral. Com isso, da população de 265 agricultores familiares da feira de Guanambi, foi estimado uma amostra de 140 para aplicação dos questionários. Em relação aos consumidores não foi possível estimar a população que frequenta a feira. Desta forma, dimensionou-se a amostra para uma população infinita, o que gerou a necessidade de, pelo menos, 276 respostas.

As informações obtidas foram analisadas com estatística descritiva e espacial. A estatística descritiva permitiu caracterizar os produtores da agricultura familiar e consumidores. A estatística espacial, por meio de mapas de calor, permitiu mostrar a influência regional do caso em estudo. Finalmente, os resultados obtidos foram comparados com a literatura pertinente.

\section{A influência dos custos de produção e de transporte para os agricultores familiares}

Os produtores cultivam frutas, legumes e hortaliças, sendo usual a produção de mais de uma cultura. Dos produtos produzidos, 38\% são legumes, 34\% são frutas e $28 \%$ hortaliças. Já entre os produtos comercializados, $47 \%$ são legumes, $30 \%$ são frutas e $23 \%$ são hortaliças. Por fim, entre os produtos mais vendidos, $45 \%$ são legumes, 39\% são frutas e $16 \%$ são hortaliças.

Os agricultores familiares cultivam esses produtos, em média, há 25 anos, sendo que o tempo mínimo exercendo a atividade é de 3 anos e o tempo máximo é de 60 anos (Figura 2a). Em relação ao tempo comercializando os produtos na feira, 
o tempo médio é de 12 anos ( $₫ 11$ anos), sendo que o tempo mínimo pesquisado é de 1 ano de atividade na feira. A quantidade de clientes no local é o principal motivo para $49 \%$ dos agricultores familiares comercializarem na feira (Figura $2 \mathrm{~b}$ ). Além disso, os agricultores consideram o ambiente agradável e frequentado por famílias e clientes que com o tempo se tornaram amigos.

Figura 2: Tempo como agricultor familiar e comercializando na Feira de Guanambi (a) e motivos para a comercialização dos produtos na Feira (b)

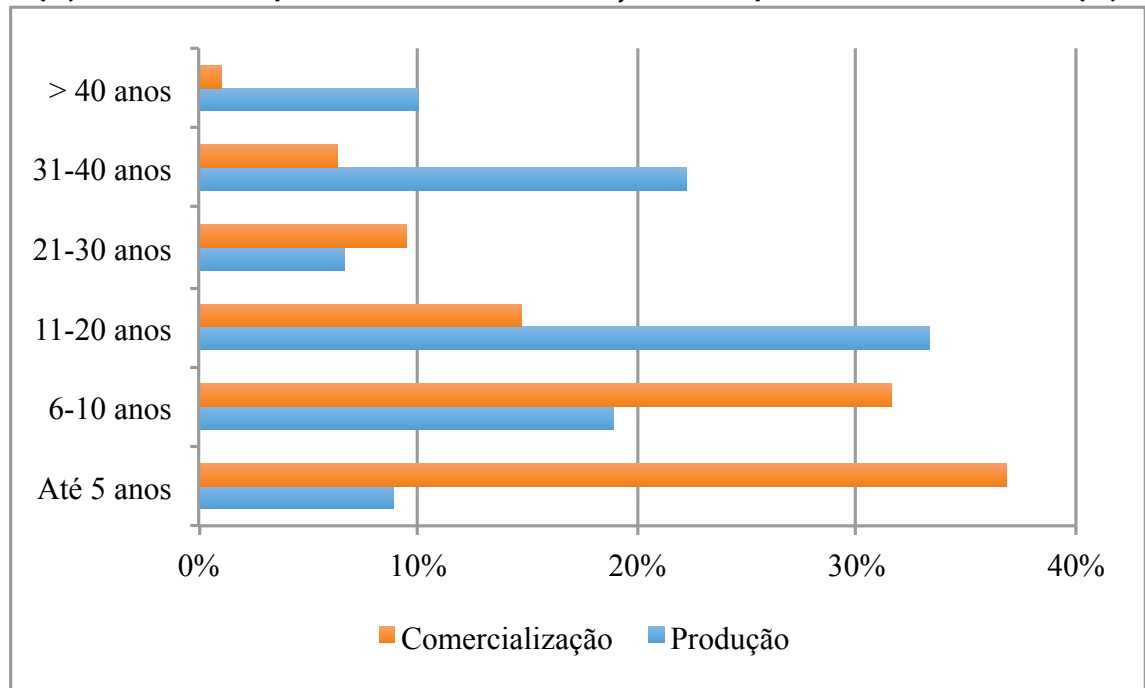

(a) tempo de produção e comercialização

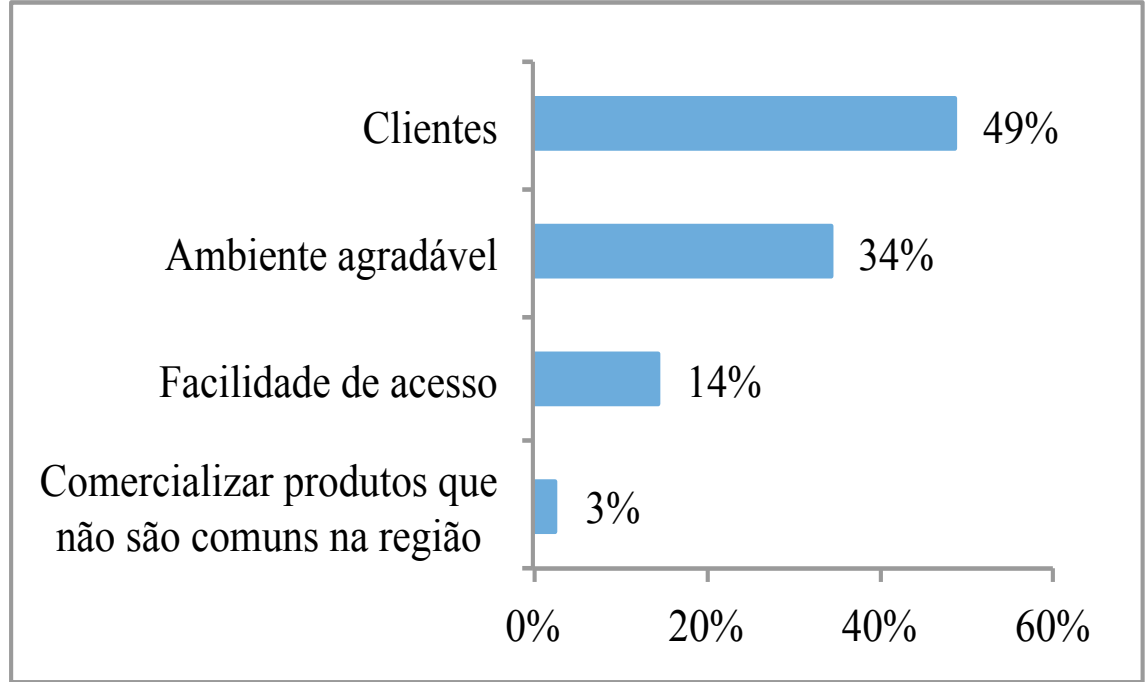

(b) motivos para comercialização na Feira

Fonte: elaborado pelos autores (2018).

Quanto à frequência com que os agricultores familiares comercializam na feira livre de Guanambi, $15 \%$ vendem todos os dias, $23 \%$ vendem três vezes por semana, $35 \%$ vendem duas vezes na semana, $24 \%$ apenas uma vez e $3 \%$ adotam outra periodicidade. Ressalta-se ainda que há comerciantes que comercializam produtos todos os dias da semana na feira livre. No entanto, os dias de maior movimento são domingos, segundas e quintas-feiras.

Com relação ao local de origem dos agricultores familiares que comercializam na feira, 30\% vêm do distrito de Morrinhos, pertencente ao próprio 
município de Guanambi. Ainda, Candiba, Ceraíma e Palmas de Monte Alto são a origem de $17 \%, 14 \%$ e $7 \%$, respectivamente, dos agricultores familiares (Figura 3). Estes resultados mostram a atratividade regional da feira no que tange aos agricultores familiares.

Figura 3: Origens dos agricultores familiares comerciantes na feira de Guanambi

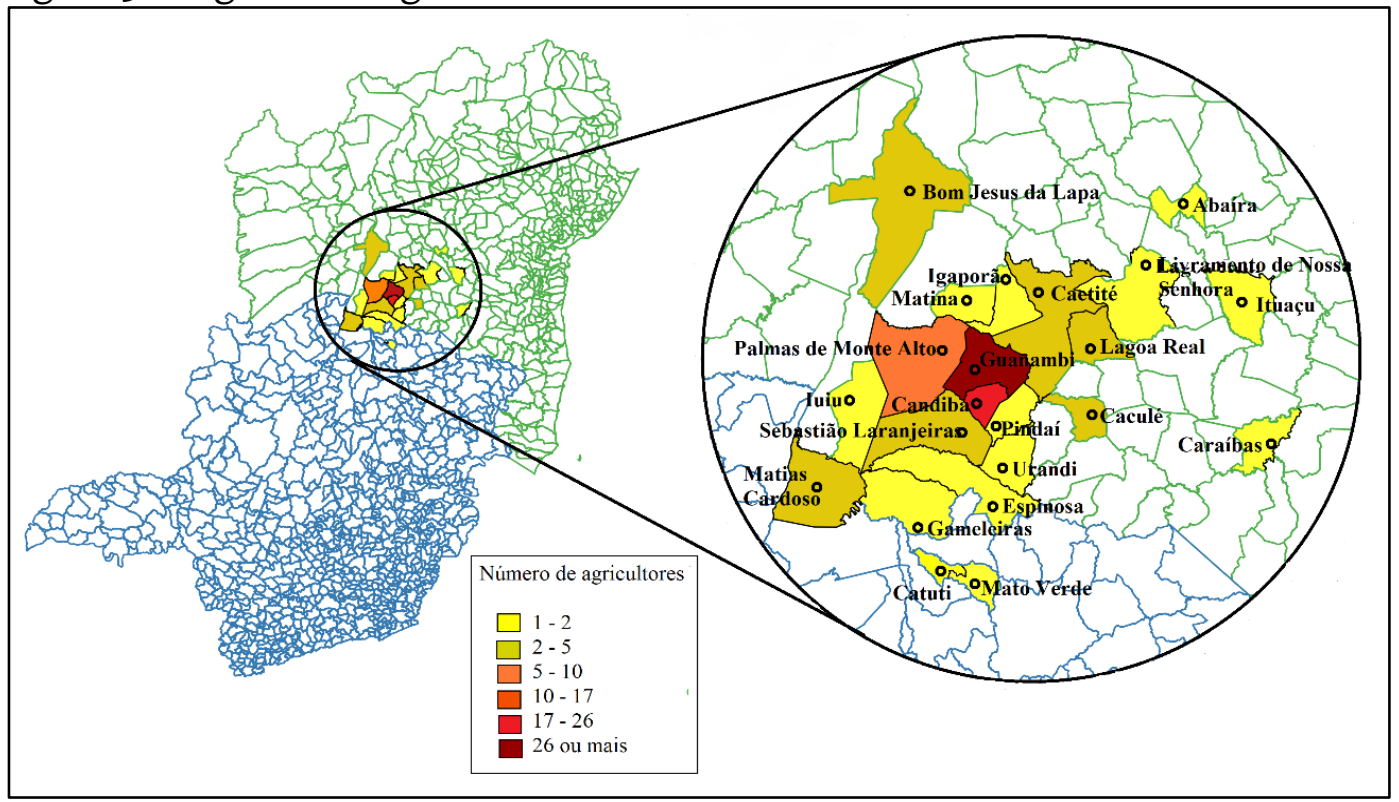

Fonte: elaborado pelos autores (2018).

O tempo médio de viagem é inferior a 60 minutos para $74 \%$ dos agricultores familiares, sendo que $39 \%$ gastam até trinta minutos durante o deslocamento, $35 \%$ gastam entre 31 e 60 minutos, $11 \%$ gasta entre 60 e 120 minutos e $15 \%$ gasta mais de duas horas. Em termos de distância, $57 \%$ dos agricultores familiares percorrem menos de 30 quilômetros, $15 \%$ percorre entre 31 e $50 \mathrm{~km}$, 9\% percorre entre 51 e $100 \mathrm{~km}, 15 \%$ entre 100 e $200 \mathrm{~km}$ e $4 \%$ percorre mais de $200 \mathrm{~km}$ para chegar em Guanambi. A correlação de Pearson entre o tempo de viagem e a distância informada pelos entrevistados é de 0,97 , indicando que os valores declarados estão relacionados. A velocidade média da amostra é de $48 \mathrm{~km} / \mathrm{h}$.

Em decorrência do número de viagens geradas pela feira livre de Guanambi, esta pode ser caracterizada como um Polo Gerador de Viagem (PGV), que são empreendimentos que atraem ou produzem grande número de viagens (OLIVEIRA et al., 2017), impactando negativamente na circulação viária do seu entorno e, em certos casos, dificultando a acessibilidade.

A análise dos impactos dos Polos Geradores de Viagem desempenha um papel importante no planejamento urbano, pois atua sobre as condições de circulação de pessoas e mercadorias (OLIVEIRA et al., 2017). Dessa forma, a identificação da área de influência do Polo Gerador de Viagem e a antecipação dos seus impactos podem subsidiar as atuações relativas ao planejamento urbano e ao desenvolvimento de políticas públicas. Assim, a Figura 4 mostra a área de influência da feira de Guanambi, considerando a origem dos agricultores familiares. Esta área equivale a $68.228 \mathrm{~km}^{2}$, aproximadamente. A sobreposição da área delimitada pelo mapa de calor da região de influência dos agricultores familiares e a delimitada pelo 
REGIC (IBGE, 2008), indica que a primeira é superior, ou seja, a feira exerce influência sobre uma área superior à área composta pelo centro sub-regional $\mathrm{B}$, os centros de zona $A$, centros de zona $B$ e sobre os centros locais determinados no estudo do REGIC.

Figura 4: Região de influência dos agricultores familiares e comparação com região delimitada pelo REGIC

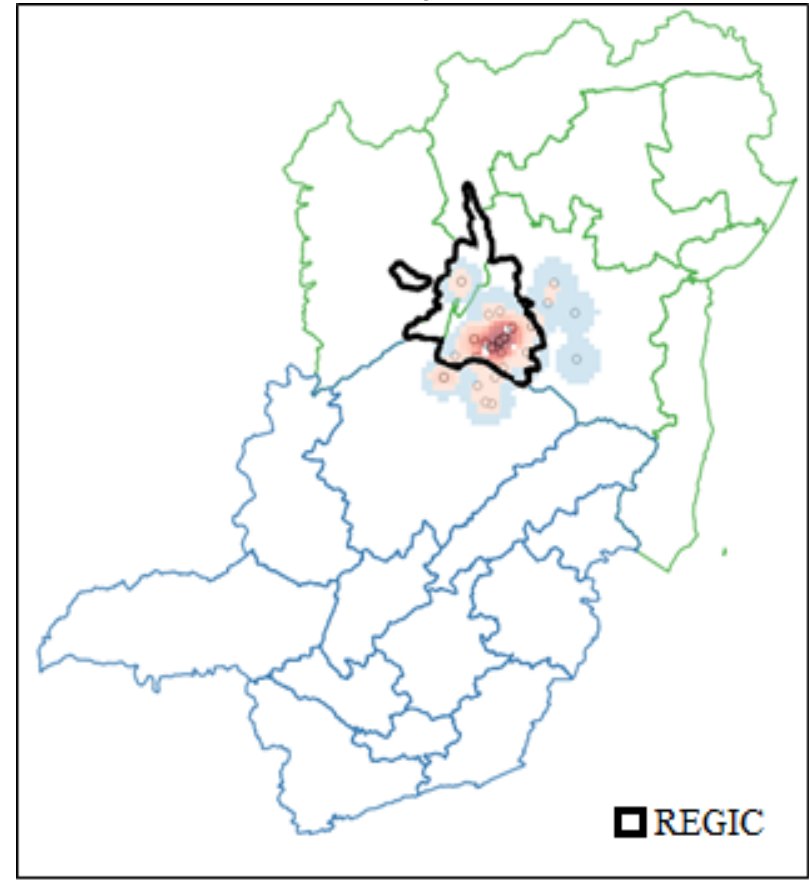

Fonte: elaborado pelos autores (2018).

Ainda segundo a pesquisa, os agricultores familiares utilizam diferentes tipos de veículos para transportar as mercadorias até a feira de Guanambi. As caminhonetes predominam, com $54 \%$ das viagens. Além disso, é comum serem utilizados "carros de frete" (com 17\% das viagens), isto é, micro-ônibus e vans fretados que realizam viagens conduzindo pessoas de localidades próximas para Guanambi. Automóveis próprios (10\%), motocicletas próprias (7\%), Kombis ( $5 \%$ ) e pessoas a pé ( $1 \%$ ) complementam a amostra pesquisada.

Uma questão econômica que chamou a atenção na pesquisa é que a maioria dos produtores entrevistados (79\%) não conhece o custo de transporte das mercadorias da propriedade rural para a feira livre de Guanambi. Os agricultores familiares que conheciam esse custo (21\%) eram, em sua maioria, aqueles que utilizavam veículos fretados e indicavam o custo pago pelo frete como o custo de transporte. Outros estimavam o custo de transporte baseando-se na distância percorrida, o consumo de combustível do veículo e o preço do combustível, desconsiderando aspectos como custos de manutenção, licenciamento, depreciação do veículo, dentre outros. A média de custo de transporte declarado é de $R \$ 18,94$, para o trajeto de ida e volta.

Outro resultado que merece destaque é que os agricultores familiares não utilizam lógica de precificação das mercadorias. Todos os entrevistados afirmaram que não sabem estimar o custo médio de produção de uma caixa do produto mais vendido na feira livre, pois, segundo eles, por se tratar de uma propriedade familiar, 
os custos variam e são distribuídos dentre as diversas culturas cultivadas no local. Os agricultores familiares informaram que não existe distinção entre o produto vendido (excedente) e o destinado ao consumo próprio. Dessa forma, não há controle de quanto é produzido para comercialização e para consumo próprio. Desta forma, é difícil estimar um valor justo e ao mesmo tempo lucrativo, por desconhecerem os custos envolvidos no processo, desde a plantação até a comercialização.

Consequentemente, os agricultores familiares tornam-se reféns dos preços dos produtos trazidos por outros feirantes de CEASAS (centrais de abastecimento regionais) para revenda e dos próprios consumidores que, por uma questão cultural, associam feira livre a baixos custos. Apesar disto, a correlação entre o preço de venda do produto mais vendido e a distância da propriedade agrícola é de 0,89 , indicando que apesar de não existir sistemática de precificação, quanto mais longe a localização da propriedade, maior é o preço de venda deste produto. Além disso, pode-se entender também que os produtos mais perecíveis (e também mais baratos), como verduras e leguminosas, são produzidos nas proximidades de Guanambi. As frutas (como abacaxi, laranja, melancia) são produzidas, em sua maioria, a mais de $100 \mathrm{~km}$ da feira de Guanambi, tendo, também, os maiores valores de venda.

Pensando em termos de desenvolvimento regional, é importante que os produtos sejam cultivados em diferentes locais e em municípios próximos como foi verificado em Guanambi. Isso é relevante para a cadeia de abastecimento e propicia melhores condições de vida para os agricultores familiares, uma vez que não os obriga a se mudar para a cidade-polo regional (que normalmente tem custo de vida mais alto). Nesse contexto, Silva e Paula (2018) salientam que o jovem rural vê ainda a possibilidade de continuar sua atividade produtiva sem abandonar a propriedade rural. Os autores complementam dizendo que essa forma descentralizada de agricultura familiar também viabiliza o cumprimento da Lei Federal nº 11.947/2009 que trata da compra de, no mínimo, 30\% dos produtos da agricultura familiar para a alimentação escolar por meio do Programa Nacional de Alimentação Escolar (PNAE) e a participação no Programa de Aquisição de Alimentos (PAA).

A pesquisa também obteve a percepção dos agricultores familiares sobre alguns problemas vivenciados na sua rotina. Essas questões influenciam, diretamente e indiretamente, o transporte das mercadorias da propriedade rural à feira livre de Guanambi. Os resultados apresentados na Tabela 1 indicam que as condições das estradas e o custo de transporte é percebido pelas pessoas como ruim e péssimo. Esta percepção faz-se verdadeira quando comparada com os resultados da pesquisa de rodovias da Confederação Nacional do Transporte (CNT, 2018), que avaliou os trechos de acesso ao município de Guanambi com estado geral regular, impactando negativamente o acesso ao município. 
Tabela 1: Problemas vivenciados pelo pequeno agricultor familiar

\begin{tabular}{l|c|c|c|c|c}
\hline \multicolumn{1}{c|}{ Problemas } & Ótimo & Bom & Ruim & Péssimo & Não sabe opinar \\
\hline Condição das estradas & $2 \%$ & $42 \%$ & $23 \%$ & $33 \%$ & $0 \%$ \\
Custo de transporte & $0 \%$ & $6 \%$ & $32 \%$ & $49 \%$ & $13 \%$ \\
Valor de venda do produto & $1 \%$ & $44 \%$ & $46 \%$ & $2 \%$ & $7 \%$ \\
Rentabilidade do negócio & $1 \%$ & $40 \%$ & $31 \%$ & $1 \%$ & $27 \%$ \\
\hline
\end{tabular}

Fonte: elaborado pelos autores (2018).

O valor de venda do produto é avaliado como ruim pelo produtor, mesmo não sabendo precificar os produtos. No entanto, os mesmos produtores percebem a rentabilidade como sendo boa. Vale comentar que o agricultor familiar que comercializa na feira livre de Guanambi paga uma taxa mensal de $\mathrm{R} \$$ 13,68 para a Prefeitura. Essa taxa serve para contribuir com os custos de manutenção do local da feira, tais como limpeza, manutenção dos banheiros e da rede elétrica. De acordo representantes da Prefeitura Municipal de Guanambi que atuam no Mercado Municipal, são gastos $\mathrm{R} \$ 80.000,00$ por mês com as despesas de manutenção do local. Além da taxa paga mensalmente à Prefeitura Municipal de Guanambi, os feirantes que utilizam balança também pagam um imposto federal ao INMETRO (Instituto Nacional de Metrologia, Qualidade e Tecnologia). Especificamente na Bahia, o órgão responsável pelo controle e fiscalização dessas balanças é o IBAMETRO (Instituto Baiano de Metrologia e Qualidade). Durante as entrevistas, verificou-se que a minoria dos agricultores familiares que comercializam na feira livre de Guanambi utiliza balanças, utilizando medidas alternativas como o litro, sacos com quantidades específicas e a contagem por dúzias.

O transporte dos produtos até a feira percebido em Guanambi é um ponto de dificuldade já relatado em outros estudos. Por exemplo, segundo Ciro et al. (2013), os agricultores de Viçosa (MG) relatam que as estradas que dão acesso às comunidades rurais de Viçosa (MG) encontram-se em más condições o que prejudica o escoamento da produção. Além disso, a gestão dos custos dos empregados na produção, incluindo transporte, não é realizada pelos produtores, o que implica em desconhecer o ganho real com a produção, fazendo com que os agricultores tenham dificuldades e insegurança no processo de vendas para o PNAE. Já segundo Izumi et al. (2008), os procedimentos logísticos para a compra de alimentos diretamente dos agricultores têm sido relatados como uma das principais preocupações e desafios na aquisição de alimentos locais.

Assim, os resultados obtidos nesta parte da pesquisa confirmam a precariedade na gestão e no controle dos custos nas propriedades agrícolas familiares, conforme identificado por Chemin e Ahlert (2010), Medeiros et al. (2012) e Santos et al. (2014). De acordo com Chemin e Ahlert (2010), frequentemente o agricultor familiar não distingue os gastos pessoais e do empreendimento, o que pode gerar prejuízos na atividade. Comumente, o pequeno agricultor não contempla todos os custos associados à atividade agrícola, tais como custos com sementes, combustível, fertilizantes, energia elétrica e depreciação de equipamentos (MEDEIROS et al., 2012), desconhecendo o custo real da produção para precificação dos produtos (SANTOS et al., 2014). Ademais, geralmente os agricultores familiares determinam os preços de venda dos seus produtos baseados 
no preço de mercado, sem especificar a ocorrência de lucro ou prejuízo (MEDEIROS et al., 2012).

Neste contexto, parece seguro afirmar que não basta apenas investir em capacitação para a produção e manejo. Deve-se investir também em capacitação de gestão da propriedade agrícola para que a atividade seja lucrativa para o agricultor familiar. Esse contexto já tinha sido explorado em outros estudos, como em Santos et al. (2019), que demonstraram a importância da gestão financeira para a agricultura familiar em sistemas agroflorestais. Nessa perspectiva, constata-se a necessidade de políticas públicas que promovam o desenvolvimento econômico dos agricultores familiares, via capacitação dos produtores, propondo alternativas sustentáveis e viáveis economicamente, conforme as especificidades locais (SANGALLI; SCHLINDWEIN, 2013).

Contudo, essa não parece ser uma tarefa fácil. Lunas et al. (2017) destacam o universo agrário brasileiro como um espaço extremamente complexo, seja em função da grande diversidade da paisagem (meio físico, ambiente, variáveis econômicas, entres outros fatores), seja em virtude da existência de diferentes tipos de atores sociais (camponês, posseiro, agricultor familiar, dentre outros), que têm interesses particulares e estratégias próprias de sobrevivência e de produção. Os níveis de escolaridade das pessoas envolvidas na atividade e a existência e constituição das instituições locais ou regionais de apoio à agricultura familiar também variam muito.

No contexto nacional, Oliveira et al. (2020) colocam que em termos de agricultura familiar distinguem-se: (a) o Programa de Aquisição de Alimentos (PAA), instituído pela Lei Federal $n^{a}$. 10.696/2003, que articula a compra de alimentos da agricultura familiar com ações de segurança alimentar para populações em situação de vulnerabilidade social; (b) o Programa Nacional de Alimentação Escolar (PNAE), que é uma das mais antigas e permanentes intervenções governamentais federais de suplementação alimentar (SPINELLI e CANESQUI, 2002) e que, desde 2009, assegura que, no mínimo, 30\% dos recursos do Fundo Nacional de Desenvolvimento da Educação (FNDE) para a alimentação escolar deve ser aplicado na aquisição de alimentos da agricultura familiar; e (c) a Compra Institucional, assegurada pelo Decreto Federal $n^{\circ}$. 8.473/2015, que estabeleceu que todos os estabelecimentos da administração federal, que compram ou forneçam alimentos, devem direcionar, igualmente, pelo menos $30 \%$ dos recursos para a agricultura familiar (SWENSSON, 2019; PEREZ-CASSARINO et al., 2018; TEO; TRICHES, 2016).

Analisando a inclusão da agricultura familiar na alimentação escolar no Estado de São Paulo, Belik e Corá (2012) apontam que apesar do objetivo da nova lei de injetar mais recursos na região por intermédio dos produtores rurais (promovendo um círculo virtuoso de aquecimento da economia local, gerando mais ocupações e oportunidades, apoiando os agricultores a ingressarem em outros mercados além do institucional), os bons propósitos na prática são de difícil realização quando se tratar de grandes municípios, com dificuldades logísticas para abastecer as escolas, dado o número de pontos de entrega, as dificuldades de armazenamento dos produtos, condições de manipulação, transporte e outros (TRICHES et al., 2019).

A questão é que nenhum desses programas e políticas públicas existentes no contexto nacional atua na questão do transporte para o agricultor familiar. Além 
disso, o Brasil é um país onde o sistema de transporte público intermunicipal de passageiros é precário e isso faz com que os agricultores familiares precisem buscar alternativas para comercializar seus produtos. Esse quadro, aliada à questão da baixa escolaridade dos agricultores familiares, dificulta ainda mais a gestão do custo real da produção e a correta precificação dos produtos.

Contudo, observam-se algumas estratégias de ordem regional/local. Por exemplo, o NEDET do Sudoeste Goiano elaborou alguns projetos para ajudar na comercialização, no armazenamento, na logística e no abastecimento de produtos da agricultura familiar (LUNAS et al., 2017). Já Oliveira et al. (2020) detalham experiências como o estabelecimento dos chamados circuitos ou canais curtos de comercialização, focados em estratégias variadas de aproximação agricultor consumidor e na prioridade ao abastecimento local e regional, na valorização da produção local e na compreensão da sazonalidade produtiva regional (MEIRELLES, 2004; PEREZ- CASSARINO, 2004; SOLER e CALLE, 2010). Neste sentido, ressalta-se a importância de desenvolver políticas públicas para implementação de programas de gestão financeira e de cálculo de custos de transportes para os agricultores familiares.

\section{A importância dos consumidores para a consolidação da agricultura familiar}

Além da caracterização do agricultor familiar comerciante na feira livre de Guanambi buscou-se ainda caracterizar os consumidores do local. Em termos de faixa etária, 3,60\% dos consumidores declararam possuir menos de 25 anos, 23,60\% entre 26 e 35 anos, $26,80 \%$ entre 36 e 45 anos, 19,60\% entre 46 e 55 anos, 18,10\% entre 56 e 65 anos e apenas 8,30\% afirmaram ter mais de 65 anos.

Os consumidores frequentam a feira livre de Guanambi principalmente aos domingos (29\%), segunda-feira (23\%) e quinta-feira (22\%), que são os principais dias da feira livre. Os frequentadores da feira de Guanambi estão à procura de frutas, verduras, hortaliças, ovos, laticínios e carnes, conforme mostra a Figura 5. Contudo, eles não adquirem estes produtos exclusivamente na feira. A maioria dos consumidores pesquisados (51,8\%) afirmaram complementar suas compras em supermercados, lojas de hortifrútis e outras feiras. 
Figura 5: Produtos adquiridos pelos consumidores

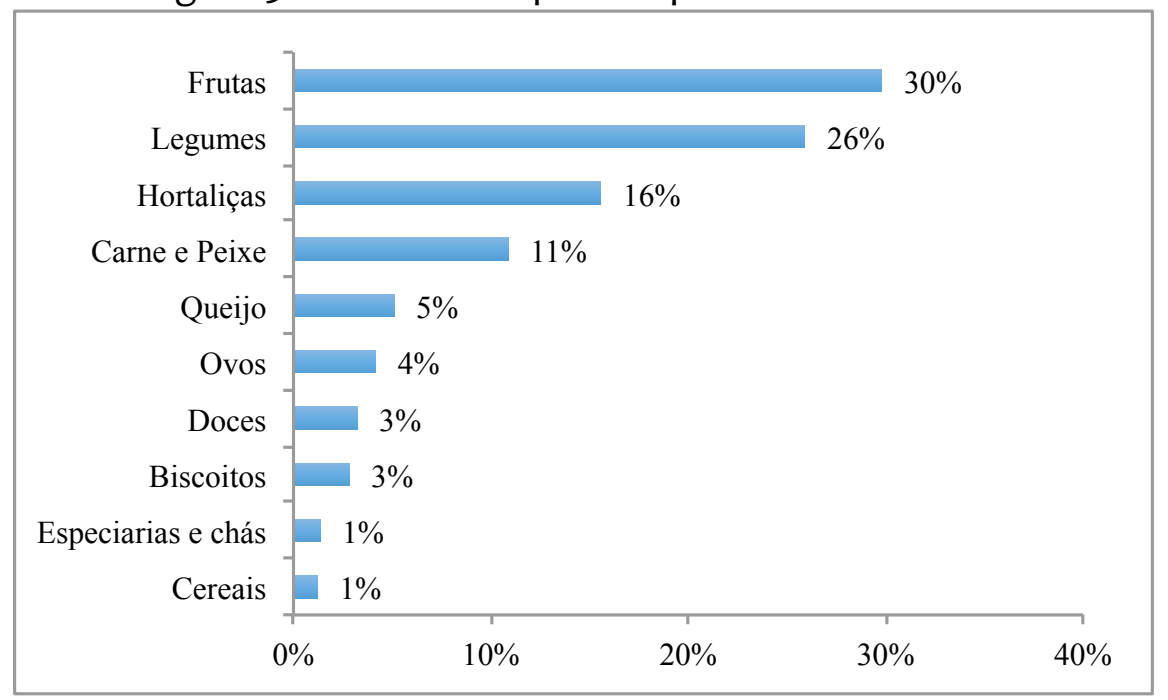

Fonte: elaborado pelos autores (2018).

Dentre as principais motivações das pessoas frequentarem e comprarem na feira livre de Guanambi, destacam-se a qualidade dos produtos (39\%) e os preços (22\%), conforme Tabela 2. Ressalta-se que dentre os entrevistados há aqueles que consideram a ida a feira um passeio, por gostarem do ambiente. A feira atua como um local de encontro com amigos, principalmente para aposentados que frequentam o lugar há vários anos. Restringindo a análise aos entrevistados que vêm de outras cidades, as motivações estão associadas à prática de outras atividades na cidade e a utilização da viagem para realizar compras no local.

\begin{tabular}{l|c} 
Tabela 2: Motivações dos clientes para comprar na feira livre de Guanambi \\
\hline \multicolumn{1}{c}{ Motivação para comprar na Feira Livre de Guanambi } & Porcentagem \\
\hline Diversidade de produtos & $17 \%$ \\
Facilidade de acesso & $4 \%$ \\
Passeio & $7 \%$ \\
Preço & $21 \%$ \\
Qualidade dos produtos & $39 \%$ \\
Realiza outras atividades na cidade e aproveita a viagem & $12 \%$ \\
\hline
\end{tabular}

Fonte: elaborado pelos autores (2018).

A origem dos consumidores da feira de Guanambi não se restringe ao seu município, como mostra a Figura 6. Os frequentadores da feira livre de Guanambi estão, em média, a 19 quilômetros do local. Guanambi (64,5\%), Candiba (10,1\%) e Palmas de Monte Alto (7,9\%) correspondem por $82,5 \%$ da origem dos entrevistados. 
Figura 6: Origem dos consumidores

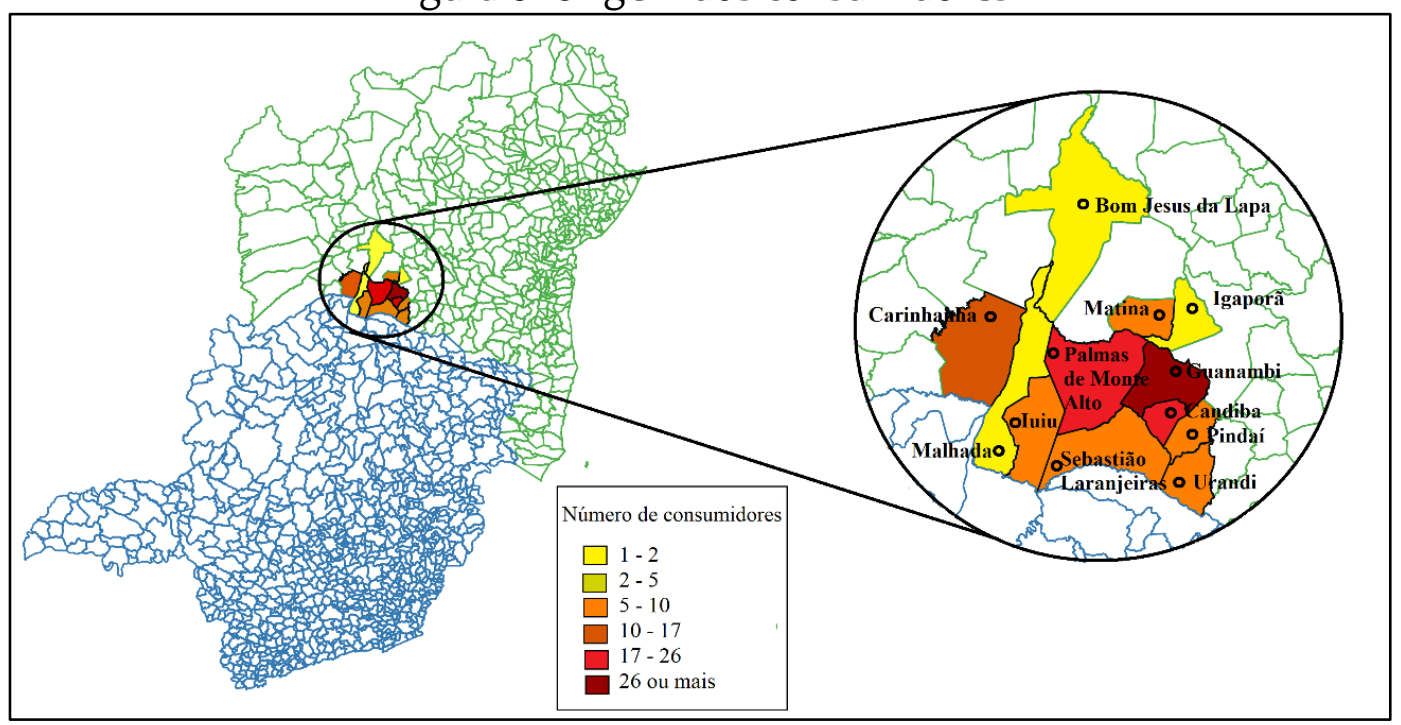

Fonte: elaborado pelos autores (2018).

Do total de consumidores entrevistados, 35\% dos entrevistados residem em outros municípios. Desta forma, pode-se inferir sobre o caráter regional da feira de Guanambi também para consumidores. Em termos relativos, do total de moradores de Guanambi, 30\% afirmaram ir à feira com automóvel próprio, 12\% com motocicleta própria, seguidos pessoas indo a pé (9\%), bicicleta (6\%), mototáxi (5\%) e transporte público (3\%), totalizando os $65 \%$. Já dos moradores de outras cidades, $23 \%$ responderam ir de "carro de frete" (veículo fretado), 8\% de automóvel próprio e 4\% de motocicleta própria, totalizando os 35\% restantes. Este resultado confirma a escassez de transporte público intermunicipal, mesmo Guanambi sendo um subcentro regional. Ainda, na pesquisa de campo observou-se em campo carência de infraestrutura de transporte como pontos de ônibus, bicicletário e ciclovia nas imediações da feira.

Do total de entrevistados que utilizam veículo próprio, $63 \%$ informaram que percebem falta de áreas para estacionamento no local. Na pesquisa de campo foi constatado que nas imediações da feira não existe distinção entre as áreas utilizadas pelos comerciantes para carga/descarga de mercadorias e as áreas destinadas ao estacionamento geral de veículos. Além disso, não há fiscalização constante no local, motivando operações de carga e descarga em locais inapropriados, desrespeitando vagas, horários e faixas de pedestres.

Os resultados referentes ao perfil do consumidor da feira de Guanambi deixam evidente que a área de influência da feira extrapola os limites do município em relação aos hábitos de compra de produtos da agricultura familiar. Os resultados ainda indicam a falta de integração regional entre as cidades (apesar da proximidade) e a dependência por modos de transporte não regulamentados, como é o caso dos veículos fretados. Em relação aos produtos, os frequentadores valorizam a agricultura familiar, consumindo produtos que são produzidos na região, como frutas, legumes e verduras.

Como os frequentadores também adquirem os mesmos produtos em outros locais, como supermercados e lojas de hortifrúti, identifica-se a necessidade de manter a qualidade dos produtos comercializados para manter a cadeia de consumo 
ativa. Por fim, devido ao elevado número de consumidores atraídos, a feira de Guanambi pode ser considerada um Polo Gerador de Viagens. Desta forma, o desenvolvimento de políticas públicas para implementação de programas de gestão financeira e de cálculo de custos de transportes pode aumentar a atratividade da feira e atuar para melhorar o desenvolvimento regional, consolidando a cidade como um importante subcentro regional.

\section{Considerações finais}

Para a análise realizada nesse artigo foram entrevistados produtores e consumidores da feira livre de Guanambi, Bahia. No que tange aos produtores da agricultura familiar, um dos principais resultados da pesquisa é o desconhecimento do custo de produção e de transporte, indicando dificuldades em termos da gestão financeira da atividade. Além disso, grande parte dos agricultores familiares têm uma produção diversificada de frutas, legumes e hortaliças. No entanto, somente o excedente é comercializado, visto que a produção destes produtores é destinada também para a subsistência.

Conterato e Bráz (2019) afirmam que em vinte anos, o Pronaf mostrou-se a principal política pública de apoio aos agricultores familiares, embora com certa timidez no que diz respeito às estruturas produtivas do rural brasileiro. Os autores complementam que o Pronaf deve ser repensado enquanto principal política pública que aporta recursos aos agricultores familiares no sentido de apoiar a diversificação produtiva e a agregação de valor. Assim, não parece sensato suspender ou encerrar o Pronaf enquanto política pública de apoio à agricultura familiar. Tendo em vista o que foi apresentado nesse artigo, a proposta é que a questão da gestão financeira e de cálculo de custos de transportes seja incluída na política pública e haja um esforço de ordem nacional para aumentar a capacitação dos agricultores familiares.

Para fomentar essa capacitação se propõe uma ampliação da atuação do chamado Sistema S para mais cidades com características de cidades-polos regionais de agricultura familiar. O Sistema $S$ possui vultosos recursos e expertise nesse tipo de capacitação profissional e seria de grande valia para aumentar a gestão financeira dos agricultores familiares. Essa ação tenderia a melhorar a competição no mercado e a preços mais justos, tanto para o produtor quanto para o consumidor.

Como sugestões para futuros trabalhos sugere-se analisar especificamente o custo de transporte de produtos originários da agricultura familiar e/ou formas alternativas para redução desse custo de transporte. Outra sugestão é a aplicação de estudo semelhante em outras cidades caracterizadas como centro sub-regional A, nas quais haja atuação agrícola familiar, utilizando a metodologia proposta nesse artigo.

\section{Agradecimentos}

Os autores agradecem ao CNPq e à Capes pelo suporte à pesquisa. 


\section{REFERÊNCIAS}

ABDULLAH, F.R.; AHAMAD, R.; ALI, S.; CHANDIO, A.A.; AHMAD, W.; ILYAS, A.; DIN, I.U. Determinants of commercialization and its impact on the welfare of smallholder rice farmers by using Heckman's two-stage approach. Journal of the Saudi Society of Agricultural Sciences, v. 18, n. 2, p. 224-233, 2017. DOI: 10.1016/j.jssas.2017.06.001

BABIGUMIRA, R.; ANGELSEN, A.; BUIS, M.; BAUCH, S.; SUNDERLAND, T.; WUNDER, $S$. Forest clearing in rural livelihoods: household-level global-comparative evidence. World Development, v. 64, n. 1, p. S67-S79. 2014. DOI: 10.1016/j.worlddev.2014.03.002

BELIK, W.; CORÁ, M.A. (Org) Projeto Nutre SP: análise da inclusão da agricultura familiar na alimentação escolar no estado de São Paulo. São Paulo: Instituto Via Pública, 2012.

BERTONI, D.; CAVICCHIOLI, D. Farm succession, occupational choice and farm adaptation at the rural-urban interface: The case of Italian horticultural farms. Land Use Policy, v. 57, p.739-748, 2016. DOI: 10.1016/j.landusepol.2016.07.002

BROMLEY, D.W. Formalising property relations in the developing world: The wrong prescription for the wrong malady. Land Use Policy, v. 26, p. 20-27, 2009. DOI: 10.1016/j.landusepol.2008.02.003

CHEMIN B.F.; AHLERT L. A sucessão patrimonial na agricultura familiar. Estudo \& Debate, v. 17, n. 1, p. 49-74, 2010.

CIRO, P.M.R.; FREITAS, A.F.; REITAS, A.F. O programa nacional de alimentação escolar como indutor de processos de desenvolvimento local em Viçosa. In: VII ENCONTRO NACIONAL DE PESQUISADORES EM GESTÃO SOCIAL, Belém, 2013.

CNT. Estatísticas consolidadas. Brasília: CNT, 2018. Disponível em https://anuariodotransporte.cnt.org.br/2018/ Acesso em: 02 out. 2020.

COELHO, V.S.P.; FAVARETO, A. Questioning the relationship between participation and development: a case study of the Vale do Ribeira, Brazil. World Development, v. 36, n. 12, p.2937-2952, 2008. DOI: 10.1016/j.worlddev.2007.11.019

CONTERATO, M.A.; BRÁZ, C.A. O processo de especialização produtiva dos agricultores familiares da Zona Sul do Rio Grande do Sul através do Pronaf-custeio. Rede: Revista do Desenvolvimento Regional, v. 24, n. 3, p.12-34, 2019. DOI: 10.17058/redes.v24i3.14001

CRUZ, M.A.; RIBEIRO, E.M.; PERONDI, M.A.; OLIVEIRA, D.C.; COSTA, H.M. Agricultura familiar, feiras livres e feirantes no Alto Jequitinhonha. CampoTerritório: Revista de Geografia Agrária, v. 15, n. 35, p.90-120, 2020. DOI: 10.14393/RCT153504 
CURRAN-COURNANE, F.; CAIN, T.; GREENHALGH, S.; SAMARSINGHE, O. Attitudes of a farming community towards urban growth and rural fragmentation: An Auckland case study. Land Use Policy, v.58, n.15, p.241-250, 2016. DOI:

10.1016/j.landusepol.2016.07.031

FAÚS, A.M. How is agriculture reproduced? Unfolding farmers' interdependencies in small-scale Mediterranean olive oil production. Journal of Rural Studies, v. 34, p. 139-151, 2014. DOI: 10.1016/j.jrurstud.2014.01.009

FERREIRA, P.A.; PEREIRA, J.R.; ALENCAR, E.; SANTANA, A.C. Estado e agricultores familiares: uma análise interpretativa sobre o desenvolvimento rural no Sul de Minas Gerais. Revista de Economia e Sociologia Rural, v. 47, n. 3, p. 769-792, 2009. DOI: $10.1590 /$ S0103-20032009000300011

GARRETT, R.D.; LAMBINI, E.F.; NAYLOR, R.L. Land institutions and supply chain configurations as determinants of soybean planted area and yields in Brazil. Land Use Policy, v. 31, p.385-396, 2013. DOI: 10.1016/j.landusepol.2012.08.002

GRANDE, J. New venture creation in the farm sector - critical resources and capabilities. Journal of Rural Studies, v. 27, n. 2, p. 220-233, 2011. DOI: 10.1016/j.jrurstud.2011.02.003

HEADEY, D.D.; JAYNE, T.S. Adaptation to land constraints: Is Africa different? Food Policy, v. 48, p. 18-33, 2014. DOI: 10.1016/j.foodpol.2014.05.005

HOLLAND, T.G.; COOMES, O.T.; ROBINSON, B.E. Evolving frontier land markets and the opportunity cost of sparing forests in western Amazonia. Land Use Policy, v. 58, p. 456-471, 2016. DOI: 10.1016/j.landusepol.2016.08.015

IBGE. Censo agropecuário 2006. Agricultura familiar primeiros resultados. Rio de Janeiro, 2006.

IBGE. Censo agropecuário 2017. Resultados preliminares. Rio de Janeiro: IBGE, 2017.

IBGE. Censo demográfico 2010. Rio de Janeiro: IGBE, 2010.

IBGE. Regiões de influência das cidades. Rio de Janeiro: IBGE, 2008.

IZUMI, B.T.; ALAIMO, K. HAMM, M. W. O35: Farm to school programs and their potential for meeting school food service goals. Journal of Nutrition Education and Behavior, v.40, n.4, S27, 2008. DOI: 10.1016/j.jneb.2008.03.047

KRISHNA, V.V.; KUBITZA, C.; PASCUAL, U.; QAIM, M. Land markets, property rights, and deforestation: insights from Indonesia. World Development. v. 99, p. 335-349, 2017. DOI: 10.1016/j.worlddev.2017.05.018 
LUNAS, D.A.L.; CARDOSO JÚNIOR, H.M.; LIMA, C.V.S. Agricultura Familiar e Desenvolvimento Territorial Rural: experiências e desafios da política pública no Sudoeste Goiano. Rede: Revista do Desenvolvimento Regional, v. 22, n. 3, p. 113-144, 2017. DOI: 10.17058/redes.v22i3.8549

MACHADO, M.D.; SILVA, A.L. Distribuição de produtos provenientes da agricultura familiar: um estudo exploratório da produção de hortaliças. Revista de Administração da UFLA, v. 6, n.1, p. 67-80, 2004.

MEDEIROS, A.F.Q.; PORTO, W.S.; SOUZA, J.A.; OLIVEIRA, D.L. Controle e apuração de resultado na agricultura familiar sob a ótica da sustentabilidade de produtores rurais. Custos e @gronegócio online,v. 8, n. 3, p. 164-171, 2012.

MEIRELLES, L. Soberania alimentar, agroecologia e mercados locais. Revista Agriculturas: experiências em agroecologia, v. 1, p. 11-14, 2004.

MICCOLI, S.; FINUCCI, F.; MURRO, R. Feeding the cities through urban agriculture the community esteem value. Agriculture and Agricultural Science Procedia, v. 8, p. 128-134, 2016. DOI: 10.1016/j.aaspro.2016.02.017

MICHALSCHECK, M.; GROOT, J.C.J.; KOTU, B.; HOESCHLE-ZELEDON, I.; KUIVANEN, K.; DESCHEEMAEKER, K.; TITTONELL, P. Model results versus farmer realities. Operationalizing diversity within and among smallholder farm systems for a nuanced impact assessment of technology packages. Agricultural Systems, v. 162, p. 164-178, 2018. DOI: 10.1016/j.agsy.2018.01.028

NASCIMENTO, F.S.; BESKOW, P. R. Comercialização e organização dos produtores agroecológicos no Rio Grande do Sul - o estudo das experiências da associação agricultores ecologistas de Ipê e Antonio Prado - AECIA e Centro de Apoio ao Pequeno Agricultor. Redes: Revista do Desenvolvimento Regional, v. 20, n. 2, p. 261282, 2015. DOI: 10.17058/redes.v20i2.2432

NEWMAN, L.; POWELL, L.; WITTMAN, H. Landscapes of food production in agriburbia: farmland protection and local food movements in British Columbia. Journal of Rural Studies, v. 39, p. 99-110, 2015. DOI: 10.1016/j.jrurstud.2015.03.006

OLIVEIRA, D.; C. GRISA; P. NIEDERLE. Inovações e novidades na construção de mercados para a agricultura familiar: os casos da Rede Ecovida de Agroecologia e da RedeCoop. Redes: Revista do Desenvolvimento Regional, v. 25 , n.1 , p. 135-163, 2020. DOI: $10.17058 /$ redes.v25i1.14248

OLIVEIRA, E.P., LIMA, B.R., BEBÉ, F.V., LIMA, P.A. Cenário da agricultura familiar no território sertão produtivo, Candiba - BA. Enciclopédia Biosfera, v. 13, n. 24, p. 262269, 2016. DOI: 10.18677/EnciBio_2016B_023 
OLIVEIRA, L.K., STUBBS, L.C.M., GONTIJO, N.T., OLIVEIRA, R.L.M. Proposição de modelos de geração de viagens para Belo Horizonte. Transportes, v. 25, n. 2, p. 137155, 2017. DOI: 10.14295/transportes.v25i2.1243

PAÜL, V.; MCKENZIE, F.H. Peri-urban farmland conservation and development of alternative food networks: Insights from a case-study area in metropolitan Barcelona (Catalonia, Spain). Land Use Policy, v. 30, p. 94-105, 2013. DOI: 10.1016/j.landusepol.2012.02.009

PEREIRA, S.R.N. A produção do espaço urbano em Guanambi. In: I CONGRESSO BRASILEIRO DE ORGANIZAÇÃO DO ESPAÇO, Rio Claro, 2010.

PEREIRA, S.R.N. Guanambi: centralidade, rede urbana e dinâmica regional no centro-sul baiano. 2013. Dissertação (Programa de Pós-Graduação em Geografia), Instituto de Geociências, Universidade Federal da Bahia, Salvador, 2013.

PEREZ-CASSARINO, J; TRICHES, R. M.; BACCARIN, J. G.; TEO, C. R. P. A. Abastecimento alimentar: redes alternativas e mercados institucionais. Chapecó: Editora UFFS; Praia, Cabo Verde: UNICV, 2018.

PEREZ-CASSARINO, J. Agroecologia e mercados locais: o caminho através da economia popular solidária. In: KÜSTER, A; MARTÍ, J. F; FICKERT, U (Orgs.). Agricultura familiar, agroecologia e mercados no Norte e Nordeste do Brasil. Fortaleza: Fundação Konrad Adenauer, 2004, p.75-83.

PETRINI, M.A., JANSLE, V.R., BROWN, J.C. Mismatches between mill-cultivated sugarcane and smallholding farming in Brazil: Environmental and socioeconomic impacts. Journal of Rural Studies, v. 50, p. 218-227, 2017. DOI: 10.1016/j.jrurstud.2017.01.009

PÖLLING, B.; SROKA, W.; MERGENTHALER, M. Success of urban farming's cityadjustments and business models - Findings from a survey among farmers in Ruhr Metropolis, Germany. Land Use Policy, v. 69, p. 372-385, 2017. DOI: 10.1016/j.landusepol.2017.09.034

RIBEIRO, E.M.; AYRES, E.C.B.; GALIZONI, F.M.; PEREIRA, V.G. Programas Sociais, mudanças e condições de vida na agricultura familiar do vale Jequitinhonha mineiro. Revista de Economia e Sociologia Rural, v.52, n. 2, p.336-386,2014. DOI: 10.1590/S0103-20032014000200009

SANGALLI, A. R.; M. M. SCHLINDWEIN. A contribuição da agricultura familiar para o desenvolvimento rural de Mato Grosso do Sul - Brasil. REDES: Revista do Desenvolvimento Regional, v. 18, n. 3, p. 82-99, 2013. DOI: 10.17058/redes.v18i3.2592

SANTOS, A. N.; PEREIRA, D.T.O.; VICTOR, P.H.A.; BORGES, F.Q. Importância da gestão financeira para agricultura familiar em sistemas agroflorestais. Revista 
Observatorio de la Economía Latinoamericana, 2019.

https://www.eumed.net/rev/oel/2019/02/gestao-financeira-agricultura.html

SANTOS, C.F., SIQUEIRA, E.S., ARAUJO, I.T., MAIA, Z.M.G. A agroecologia como perspectiva de sustentabilidade na agricultura familiar. Ambiente \& Sociedade São Paulo, v. 17, n. 2, p. 33-52, 2014. DOI: 10.1590/S1414-753X2014000200004

SANTOS, J.R., DIAS, F.S., FINATO, K.M., FERREIRA, J.A.C. Efeitos da densidade populacional e proximidade de aglomerados urbanos sobre o nível de efetividade do Programa de Aquisição de Alimentos (PAA) no Brasil. Scientia Plena, v. 11, n. 2, p. 1-11, 2015.

SIDE. Sistemas de Dados Estatísticos. Disponível em:

http://www.sei.ba.gov.br/side/index.wsp Acesso em: 02 oct. 2020.

SILVA, J.L.G.; PAULA, M.M. Articulação dos atores institucionais no desenvolvimento da agricultura familiar no Sudoeste Goiano. Redes: Revista do Desenvolvimento Regional, v. 23, n.1, p. 92-110, 2018. DOI: 10.17058/redes.v23i1.8465

SOLER, M.; CALLE, A.C. Rearticulando desde la alimentación: canales cortos de comercialización en Andalucía. PH Cuadernos, v. 26, p. 259-283, 2010.

SPINELLI, M.A.S.; CANESQUI, A.M. O programa de alimentação escolar no estado de Mato Grosso: da centralização à descentralização (1979-1995). Revista de Nutrição, v. 15, n. 1, p. 105-117, 2002. DOI: 10.1590/S1415-52732002000100011.

SWENSSON, L.F.J. Programas institucionais de aquisição de alimentos e organizações de produtores: catalisadores para a transformação de sistemas de abastecimento de alimentos de pequenos produtores. Redes: Revista do Desenvolvimento Regional, v. 24, n. 1, p. 30-44, 2019. DOI:

10.17058/redes.v24i1.13041

TAIWO, O.J. Determinants of peri-urban and urban agricultural locational choice behaviour in Lagos, Nigeria. Land Use Policy, v. 39, p. 320-330, 2014. DOI: 10.1016/j.landusepol.2014.02.003

TEO, C.R.P.A.; TRICHES, R.M. Alimentação escolar construindo interfaces entre saúde, educação e desenvolvimento. Chapecó: Argos, 2016.

TRICHES, R.M.; Simonetti, M.G.; Cassarino, J.P.; Baccarin, J.G.; Teo, C.R.P.A. Condicionantes e limitantes na aquisição de produtos da agricultura familiar pelo Programa de Alimentação Escolar no Estado do Paraná. Redes: Revista do Desenvolvimento Regional, v. 24, n. 1, p. 118-137, 2019. DOI:

10.17058/redes.v24i1.11713 
VANDERCASTEELEN, J.; BEYENE, S.T.; MINTEN, B.; SWINNEN, J. Cities and agricultural transformation in Africa: evidence from Ethiopia. World Development, v. 105, p. 383-399, 2017. DOI: 10.1016/j.worlddev.2017.10.032

WÄSTFELT, A.; ZHANG, Q. Reclaiming localisation for revitalising agriculture: A case study of peri-urban agricultural change in Gothenburg, Sweden. Journal of Rural

Studies, v. 47, p. 172-185, 2016. DOI: 10.1016/j.jrurstud.2016.07.013

Leise Kelli de Oliveira. Doutora em Engenharia de Produção. Universidade Federal de Minas Gerais. Professora Associada. leise@etg.ufmg.br

Isadora Alves Barbosa. Mestre em Geotecnia e Transportes. Universidade Federal de Minas Gerais. alves.isa@hotmail.com.br

Leonardo Herszon Meira. Doutor em Engenharia Civil. Universidade Federal de Pernambuco.Professor Adjunto. leonardo.meira@ufpe.br

Isabelly Christiny Monteiro de Souza Pinto. Mestre em Engenharia Civil. Universidade Federal de Pernambuco. Doutoranda em Engenharia Civil. isabellycmsp@gmail.com

Como citar: OLIVEIRA, Leise Kelli de et al. Influência dos custos de produção e de transporte para a agricultura familiar e sua relação com o desenvolvimento regional: o caso da feira municipal de Guanambi (BA). Redes (St. Cruz Sul, Online), Santa Cruz do Sul, v. 25, p. 21052127, 2020. ISSN 1982-6745. doi:https://doi.org/10.17058/redes.v25io.14953.

\section{CONTRIBUIÇÃO DE CADA AUTOR}

a. Fundamentação teórico-conceitual e problematização: Isadora A. Barbosa, Leise K. Oliveira e Leonardo H. Meira.

b. Pesquisa de dados e análise estatística: Isadora A. Barbosa e Leise K. Oliveira.

c. Elaboração de figuras e tabelas: Isadora A., Barbosa, Leise K. Oliveira, Leonardo H. Meira e Isabelly C. M. S. Pinto.

d. Elaboração e redação do texto: Isadora A. Barbosa, Leise K. Oliveira, Leonardo H. Meira e Isabelly C. M. S. Pinto.

e. Seleção das referências bibliográficas: Isadora A. Barbosa e Leonardo H. Meira.

Fontes de financiamento: CNPq; CAPES 